Spotlight on the May 31 Issue

\author{
Robert A. Gross, MD, PhD, FAAN \\ Editor-in-Chief, Neurology ${ }^{\circledR}$
}

\section{Disease activity return during natalizumab treatment interruption in patients with multiple sclerosis the}

Clinical relapses of 1866 patients and gadolinium-enhanced $(\mathrm{Gd}+)$ lesions of 341 patients were analyzed over an 8-month period. This paper provides evidence that when you stop Tysabri in patients with multiple sclerosis, clinical and MRI activity gradually returns to pre-study baseline activity over 3-4 months. See p. 1858; Editorial, p. 1854

\section{Stress and the risk of multiple sclerosis}

Several studies have shown that stressful life events are associated with an increased risk of multiple sclerosis (MS) exacerbations. This study found, in two cohorts of female nurses, that there was no increased risk of MS in those with severe stress at home, severe physical abuse during childhood or those forced into sexual activity in childhood. See p. 1866

Incident lacunes influence cognitive decline: The LADIS study pit

This first paper investigated the contribution of lacunar infarcts in longitudinal cognitive change in 387 elderly subjects. Incident lacunes paralleled steeper decline of psychomotor speed and executive functions, thus determining progressive cognitive impairment in cerebral small vessel disease.

See p. 1872; Editorial, p. 1856; see also p. 1879

\section{Vascular risk factors and longitudinal changes on brain} MRI: The ARIC study

Epidemiological studies provide a broader view of vascular risk factors than overt strokes. This second paper showed that diabetes and hypertension in midlife were associated with infarcts and loss of brain volume in brain MR scans 10 years later.

See p. 1879; Editorial, p. 1856; see also p. 1872

From editorialists Filley and Brodtmann: "Using longitudinal designs requiring many years of follow-up, these articles provide evidence supporting the notion that lacunar strokes can negatively affect processing speed and executive function, and that hypertension and diabetes are of etiologic importance."

See p. 1856

\section{Predicting survival in frontotemporal dementia with motor neuron disease [}

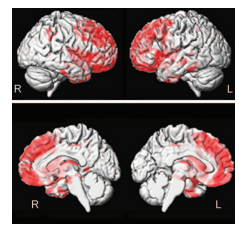

The authors demonstrated that patients with frontotemporal dementia and motor neuron disease with prominent language impairment have shorter survival than patients with prominent behavioral impairment, in part due to bulbar onset symptoms. This finding has prognostic importance. See p. 1886

\section{Real-life driving outcomes in Parkinson disease}

This prospective cohort study ascertained the time until driving cessation, a crash or a traffic citation in 106 active drivers with Parkinson disease and in 130 controls. Severity of parkinsonism, visual and cognitive dysfunction, older age, worse road performance, and driving history at baseline were associated with driving cessation in this group. See p. 1894

\section{Clinical and MRI characteristics of acute migrainous infarction}

The authors investigated clinical and MR imaging characteristics in 17 patients with migraine associated acute cerebral ischemia, from 8137 stroke patients over an 11 year period. Their findings support previous observations that migrainous infarction mostly occurs in the posterior circulation, and in younger women with a history of migraine with aura. See p. 1911

VIEWS \& REVIEWS

Abbreviated report of the NIH/NINDS workshop on sudden unexpected death in epilepsy

Sudden unexpected death in epilepsy (SUDEP) is not rare. This multidisciplinary workshop was held to advance research into SUDEP and its prevention. Scientific sessions covered potential causes and education sessions covered when and how to discuss SUDEP. Suggestions for further research and prevention were outlined.

See p. 1932

NB: "Resident \& Fellow Clinical Reasoning: A young adult presents with focal weakness and hemorrhagic brain lesions," see $p$. e106. To check out other Resident \& Fellow submissions, point your browser to http://www.neurology.org and click on the link to the Resident and Fellow Section. Access the podcast at www.neurology.org. 


\section{Neurology}

\section{Spotlight on the May 31 Issue}

Robert A. Gross

Neurology 2011;76;1853

DOI 10.1212/WNL.0b013e31821de7ef

\section{This information is current as of May 30, 2011}

\section{Updated Information \&} Services

Permissions \& Licensing

Reprints including high resolution figures, can be found at: http://n.neurology.org/content/76/22/1853.full

Information about reproducing this article in parts (figures,tables) or in its entirety can be found online at:

http://www.neurology.org/about/about_the_journal\#permissions

Information about ordering reprints can be found online:

http://n.neurology.org/subscribers/advertise

Neurology ${ }^{\circledR}$ is the official journal of the American Academy of Neurology. Published continuously since 1951, it is now a weekly with 48 issues per year. Copyright Copyright $@ 2011$ by AAN Enterprises, Inc.. All rights reserved. Print ISSN: 0028-3878. Online ISSN: 1526-632X.

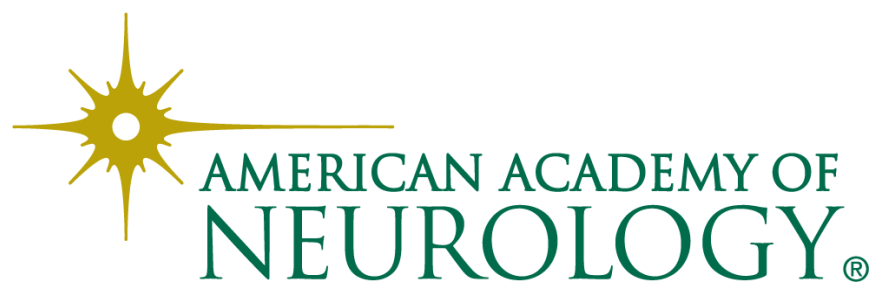

